\title{
A 14-year-old boy presenting with gradual abdominal distension and occasional abdominal pain for 2 years
}

\author{
Nazmul Hassan, Mahmudul Hasan, Kaniz Fathema, Khondaker Mobasher, Fahmida Begum and \\ Wahiduzzaman Mazumder
}

\begin{abstract}
Article Info
Department of Pediatric Gastroenterology and Nutrition, Faculty of Pediatrics, Bangabandhu Sheikh Mujib Medical

University, Shahbag, Dhaka, Bangladesh

For Correspondence:

Md. Nazmul Hassan

nahidnazmul33@gmail.com

Received:

Accepted:

Available Online:

2 September 2019 12 December 2019 25 December 2019
\end{abstract}

ISSN: 2224-7750 (Online) 2074-2908 (Print)

DOI: 10.3329/bsmmuj.v12i4.44550

Keywords: Abdominal distension; Budd -Chiari syndrome; Hepatomegaly; Pain; Spleen; Thrombophilia

\section{Cite this article:}

Hassan N, Hasan M, Fathema K, Begum F, Mazumder W, Mobasher K. A 14-year -old boy presenting with gradual abdominal distension and occasional abdominal pain for 2 years. Bangabandhu Sheikh Mujib Med Univ J. 2019; 12: 204-210.

\section{Copyright:}

The copyright of this article is retained by the author(s) [Atribution CC-By 4.0]

\section{Available at:}

www.banglajol.info

A Journal of Bangabandhu Sheikh Mujib Medical University, Dhaka, Bangladesh

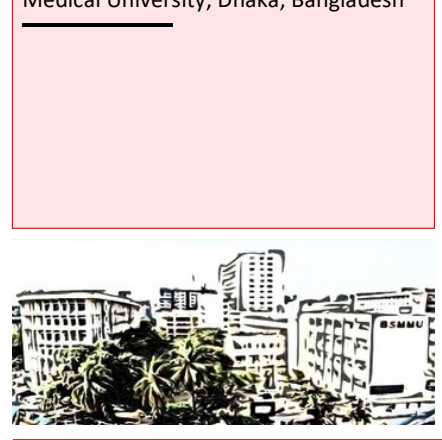

\section{Presentation of Case}

Dr. Md. Nazmul Hassan (Resident): A 14-yearold boy, $4^{\text {th }}$ issue of his non-consanguineous parents got admitted in the Department with the complaints of gradual abdominal distension and occasional abdominal pain since two years of his age. There was no history of jaundice, upper gastrointestinal bleeding, fever, contact with a known case of tuberculosis patient or family history of such type of illness. On examination, he was alert, anicteric, no facial dysmorphism, vitally stable, no stigmata of chronic liver disease and anthropometrically well thrived. On alimentary system examination, the abdomen was hugely distended, visible engorged vein (Figure 1), hepatomegaly $(10 \mathrm{~cm})$, spleen just palpable and huge ascites was present. Other systemic examination revealed no abnormality. Routine laboratory investigations showed hemoglobin was $11.4 \mathrm{~g} / \mathrm{dL}$; a total leucocyte count was 6,500 cells $/ \mathrm{mm}^{3}$ and among, neutrophils were $44 \%$ and lymphocytes $49 \%$. The erythrocyte sedimentation rate was 40 $\mathrm{mm}$ in $1^{\text {st }}$ hour and platelet count was $136 \times$ $10^{9} / \mathrm{mm}^{3}$. The liver function tests showed serum albumin $(41 \mathrm{~g} / \mathrm{L})$, prothrombin time

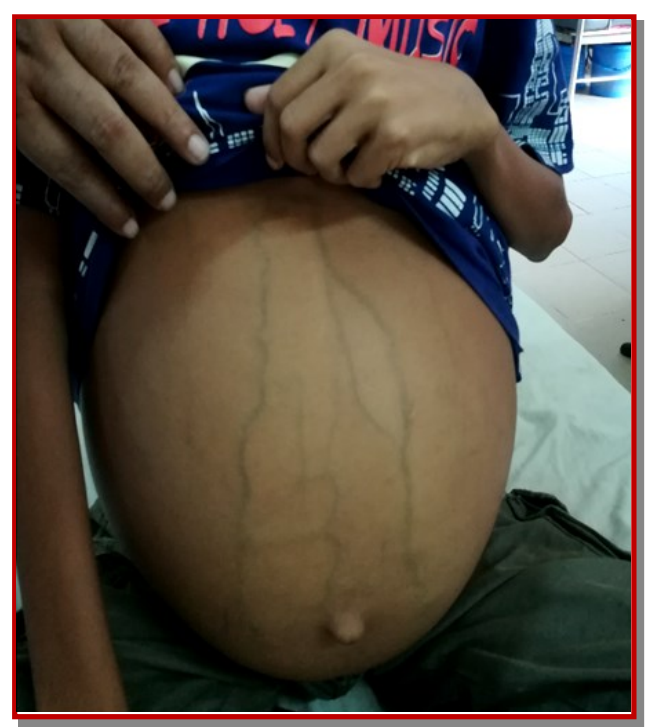

Figure 1: Distended abdomen, visible engorged vein and huge ascites
(14.8 sec), international normalized ratio 1.25 and normal alanine aminotransferase level (9 $\mathrm{U} / \mathrm{L}$ ). Serum electrolyte and creatinine levels were also normal. The ascitic fluid examination showed total cell count of 160 cells $/ \mathrm{mm}^{3}$ with $10 \%$ polymorph nuclear neutrophils and $90 \%$ lymphocytes. The biochemical examination showed the protein level was $5.5 \mathrm{~g} / \mathrm{dL}$ and the sugar level was $5.3 \mathrm{~g} / \mathrm{dL}$. The adenosine deaminase level was normal. The serum ascites albumin gradient was high of 1.5 (>1.1). Endoscopy of the upper gastrointestinal tract revealed a developing varix (Figure 2A). Ultrasonography of the abdomen showed hepatosplenomegaly with huge ascites. Color doppler study showed a compressed middle hepatic vein due to enlarged caudate lobe $(8.5 \times 3.9 \mathrm{~cm})$, loss of normal flow characteristics, hepato-fugal flow direction and features of mild portal hypertension but no thrombosis was found. Computer tomography venogram of the liver revealed portal vein was dilated, tortuous and produced varices along with the spleno-portal circulation (Figure 2B). Mantoux test and Chest $\mathrm{X}$-ray were normal. Blood for inherited deficiency revealed a deficiency of protein $S$ and antithrombin III but protein C was normal (Table I)

\section{Provisional Diagnosis}

Budd-Chiari syndrome most probably due to inherited thrombophilia (deficiency of protein C, protein S and antithrombin III)

\section{Differential Diagnosis}

Dr. Mahmudul Hasan (Resident): As the patient was having a history of gradual abdominal distension and occasionally abdominal pain and on examination hepatosplenomegaly and ascites present, we differentially thought about chronic liver disease.

Dr. Kaniz Fathema (Resident): As Bangladesh is a highly endemic zone for tuberculosis and patient having gradual abdominal distension, occasional abdominal pain along with hepato- 
Table I

\begin{tabular}{|c|c|c|}
\hline \multicolumn{3}{|c|}{ Investigation reports of the patient } \\
\hline Parameters & Findings & References \\
\hline Total white blood cell count $\left(/ \mathrm{mm}^{3}\right)$ & 6,500 & $4,500-11,000$ \\
\hline \multicolumn{3}{|l|}{ Differential count } \\
\hline Neutrophil (\%) & 44 & $40-80$ \\
\hline Lymphocyte (\%) & 49 & $20-40$ \\
\hline Platelet $\left(/ \mathrm{mm}^{3}\right)$ & 136,000 & $150,000-400,000$ \\
\hline $\begin{array}{l}\text { Erythrocyte sedimentation rate ( } \mathrm{mm} \text { in } \\
\text { first hour) }\end{array}$ & 40 & $0-10$ \\
\hline Hemoglobin $(\mathrm{g} / \mathrm{dL})$ & 11.4 & $13-17$ \\
\hline Serum albumin $(\mathrm{g} / \mathrm{L})$ & 41 & $35-50$ \\
\hline Prothrombin time (sec) & 14.8 & $12-16$ \\
\hline International normalized ratio & 1.25 & $<1.4$ \\
\hline Serum alanine aminotransferase (U/L) & 9 & $35-50$ \\
\hline Serum creatinine $(\mathrm{mg} / \mathrm{dL})$ & 0.52 & $0.9-1.3$ \\
\hline \multicolumn{3}{|l|}{ Ascitic fluid study } \\
\hline Color & Straw & \\
\hline Total white blood cell count $\left(/ \mathrm{mm}^{3}\right)$ & 160 & \\
\hline \multicolumn{3}{|l|}{ Differential count } \\
\hline Neutrophil (\%) & 10 & \\
\hline Lymphocyte (\%) & 90 & \\
\hline Total protein $(\mathrm{g} / \mathrm{L})$ & 55 & \\
\hline Ascitic fluid albumin $(\mathrm{g} / \mathrm{L})$ & 26 & \\
\hline Glucose $(\mathrm{g} / \mathrm{L})$ & 5.3 & \\
\hline Adenosine deaminase (U/L) & 13.1 & $<24$ \\
\hline Protein C (\%) & 83 & $70-140$ \\
\hline Protein S (\%) & 60 & $70-140$ \\
\hline Antithrombin III (\%) & 72 & $80-120$ \\
\hline
\end{tabular}

splenomegaly and ascites, so after evaluating the other features, it could be a case of abdominal tuberculosis.

\section{Budd-Chiari syndrome}

Dr. Hassan: Budd-Chiari syndrome is a rare heterogeneous disease characterized by obstruction of the hepatic venous outflow tract in the absence of constrictive pericarditis or right heart failure. It may be thrombotic or non-thrombotic anywhere along the venous course from the hepatic venules to the junction of the inferior vena cava with the right atrium. Hepatic veno-occlusive disease and cardiac disorders are not included in the definition. The classical Budd-Chiari syndrome is characterized clinically by a triad of ascites, hepatomegaly and right upper quadrant pain. It is an uncommon but important syndrome because of many disorders. It may be associated with several hematologic or malignant diseases.1-3 In the late 1800s, the term Budd-Chiari was first named after a British inter- nist, George Budd, described three cases of hepatic vein thrombosis due to abscess-induced phlebitis and in 1899 Austrian pathologist Hans Chiari, added the first pathologic description of a liver with obliterating endophlebitis of the hepatic veins. $\underline{4}$ The prevalence of Budd-Chiari syndrome is $1 / 100,000$ among the general population worldwide. 5 Compared to adults, it is very uncommon in children. Most of the cases of classic Budd-Chiari syndrome occur between the ages of 20 and 39 years and only $5 \%$ were found be below 12 years of age.6-8 The syndrome can be classified as: a) Primary (intraluminal obstruction by a thrombus or web) or b) secondary (extrinsic compression by an abscess, tumor, cyst, or hyperplastic nodules).., 8 Clinically, it can be presented as a) Acute- develops usually within 1 month or symptomatic for less than 6 months and characterized by intractable ascites, abdominal pain, liver enlargement, renal failure, elevation of hepatic enzymes and coagulopathy; -9 b) subacute- which is insidious onset. It may take as long as 3 months to become asymptomatic, usually having minimal/trace or no ascites but do not have esophageal bleeding; $; 0$ c) chronic- disease duration of 6 or more months or signs of portal hypertension present.11 For diagnostic evaluation of Budd-Chiari syndrome, the first step is the doppler ultrasonography of the hepatic vessels and inferior vena cava, which in $95 \%$ cases establish the diagnosis. In doppler ultrasonography, highly specific findings for Budd-Chiari syndrome are stenosis, thrombosis, fibrotic cord, or insufficient recanalization of the vessel in the hepatic or caval veins, along with caudate lobe hypertrophy. $\underline{.2}$

\section{Chronic liver disease}

Dr. Mahmud: Chronic liver disease comprises both chronic hepatitis and cirrhosis. Cirrhosis is defined as a diffuse liver process where fibrosis has resulted in a conversion of the liver architecture into structurally abnormal nodules. $\underline{13}$ In children, a wide range of causes of hepatocellular injury present that include causes of cholestasis, infection, toxin, metabolic, vascular, and nutritional disorders that may result in cirrhosis of the liver. Irrespective of the cause of chronic injury, and in the absence of removal of the cause of injury, the cirrhotic state and many complications persist. $\underline{4}$ The diagnosis is based on the combination of clinical (stigmata of chronic liver disease), biochemical (liver function tests) and imaging findings. Unfortunately, available therapies for many chronic liver diseases causing cirrhosis in children are ineffective. The treatment is limited to the management of these secondary pathophysiological complications and liver transplantation is the only available definitive option when the liver failure established. $1 \underline{\underline{15}}$

\section{Abdominal tuberculosis}

Dr. Fathema: Disseminated abdominal tuberculosis involves the gastrointestinal tract, peritoneum, 


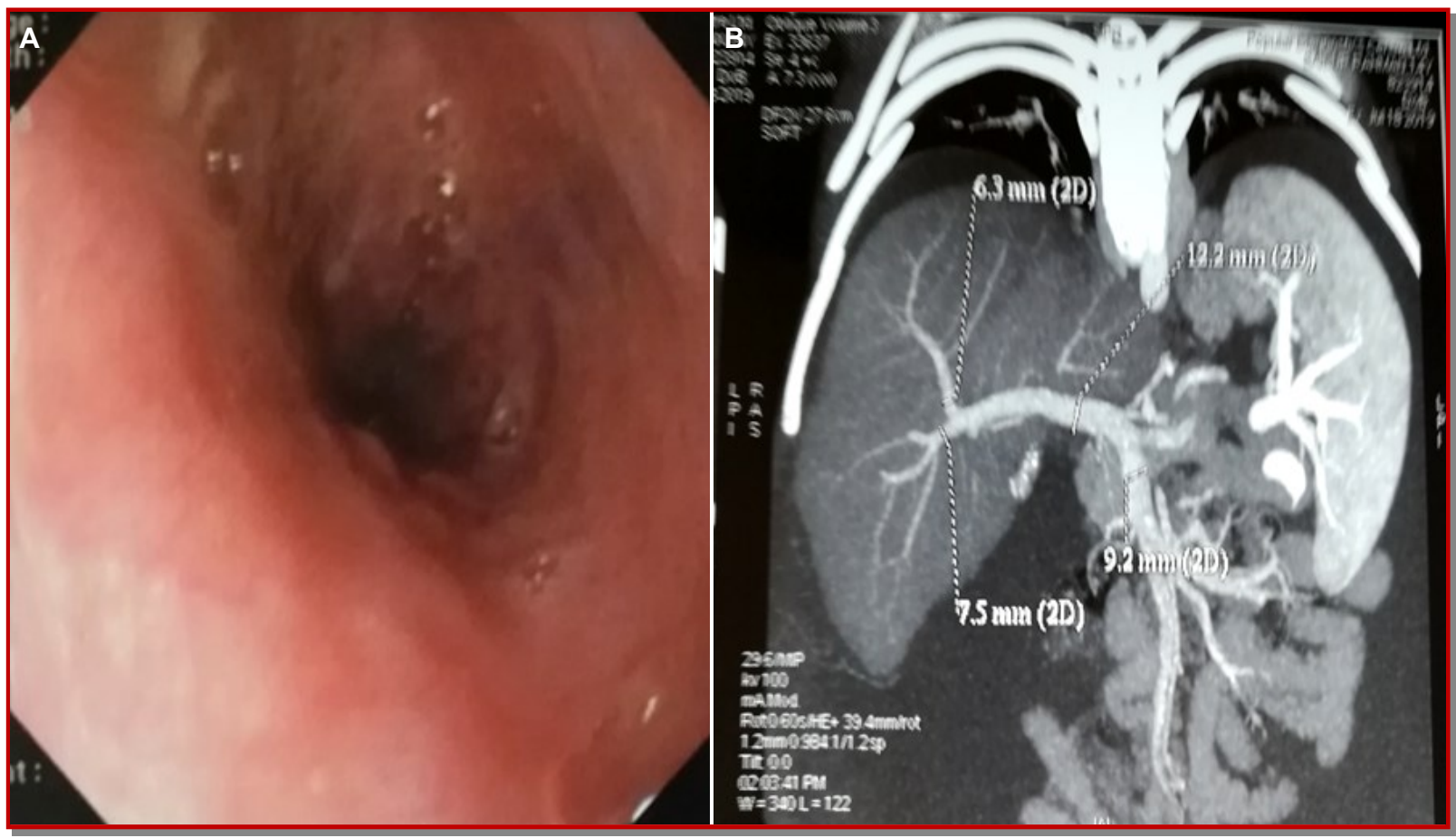

Figure 2: Endoscopic examination of esophagus showing the developing varix (A); CT venogram of hepatobiliary system (B)

lymph nodes and solid viscera. $\underline{16}$ In children, the number of extra-pulmonary tuberculosis cases is higher compared to pulmonary tuberculosis. 17 It is difficult to diagnose childhood tuberculosis because of non-specific clinical findings as well as low-quality of sampling, paucibacillary and lack of $\mathrm{Myco-}$ bacterium culture facilities. $\underline{18}$ Tuberculous bacilli can spread into the abdomen and gastro-intestinal tract by the following route: a) hematogenous spread from the lung focus, $b$ ) ingestion of bacilli from the infected sputum, c) unpasturized cow's milk ingestion, and d) direct spread from adjacent infected structures. 19 Anorexia, malaise, low grade fever, weight loss and abdominal distension due to ascites are the non-specific symptoms of abdominal tuberculosis. Physical examinations may reveal cachexia, fever, lymphadenopathy, absent BCG mark, hepatomegaly, splenomegaly, ascites and features of intestinal obstruction.

Dr. Khondaker Mobasher (Resident): After evaluating the patient's presenting features, physical findings as patient having no stigmata of chronic liver disease and the liver function tests showed serum albumin $(41 \mathrm{~g} / \mathrm{L})$, prothrombin time $(14.8 \mathrm{sec})$, normal alanine aminotransferase level $(9 \mathrm{U} / \mathrm{L})$ and ultrasonography of the abdomen showed hepatosplenomegaly and huge ascites but hepatic architecture was normal. So, chronic liver disease was excluded.

Our patient was presented with ascites and hepatosplenomgaly which are suggestive but no history of cow's milk ingestion, no contact history with tuberculosis patient, absence of growth failure and no lymphadenopathy go against the diagnosis of disse- minated abdominal tuberculosis. To reach the other differential (abdominal tuberculosis), we did complete blood count, ascitic fluid study, serum ascites albumin gradient, Monteux test and chest X-ray which were normal. So, abdominal tuberculosis was also excluded.

Prof. A. K. M. Fazlul Bari: To establish our provisional diagnosis, we do the color doppler study of portal vein, hepatic veins and inferior vena cava which showed middle hepatic vein was compressed due to enlarged caudate lobe, loss of normal flow characteristics, hepatofugal flow direction along with caudate lobe hypertrophy and features of mild portal hypertension but no thrombosis was found.

Dr. Hassan: According to the color doppler study, we finally diagnosed it as a case of Budd-Chiari syndrome. To find out the cause as well as site of thrombosis, we do the computer tomography venogram of the liver revealed portal vein was dilated, tortuous and produces varices along with the splenoportal circulation. Blood for inherited deficiency revealed deficiency of protein $S(60 \%)$ and antithrombin III $(72 \%)$ but protein C $(83 \%)$ was normal. We also did the endoscopy of upper gastrointestinal tract which revealed developing esophageal varices.

\section{Dr. Hasan's Diagnosis}

Chronic Budd-Chiari syndrome due to inherited thrombophilia (deficiency of protein $S$ and antithrombin III) 


\section{Discussion}

The child was treated with diuretics and therapeutic paracentesis.

Dr. Fahmida Begum (Associate Professor): Hepatic venous outflow tract obstruction is another synonym of Budd-Chiary syndrome.1-3 In our case, hepatic venous flow was obstructed due to compression of middle hepatic vein by caudate lobe. Disease manifestation of our case was started since two years of his age.

In Budd-Chiari syndrome portal vein and hepatic sinusoidal pressures increases because of the stagnation of blood flow due to the obstruction of hepatic venous outflow tract from the venules to the right atrium. Portal pressure increases gradually and thus perfusion of the liver via portal vein is decreased, resulting in liver congestion, right upper quadrant pain and ascites. In both the acute and chronic forms, obstruction leads to centrilobular necrosis and peripheral lobular fatty change due to hypoxic damage of hepatocytes followed by ischemia. If this condition persists a long time during disease progressive fibrosis, nodular regenerative hyperplasia, and ultimately may develop cirrhosis and portal hypertension. $.3,20$ The caudate lobe, which has direct venous drainage into the inferior vena cava, often undergoes compensatory hypertrophy, causes inferior vena cava stenosis.21 In this case, features of portal hypertension were found by upper gastrointestine endoscopy and also disease duration for more than 6 months, so it is a chronic case of Budd-Chiari syndrome.

Dr. Md. Wahiduzzaman Mazumder (Associate Professor): Budd-Chiari syndrome may be fulminant $(5 \%)$, acute $(20 \%)$, subacute or chronic $(60 \%)$ and may be asymptomatic (15-20\%) of cases approximately. $\underline{10,22}$ It most often presents as chronic obstruction with abdominal distension, hepatomegaly, ascites and abdominal pain. Other clinical manifestations may be jaundice, upper gastrointestinal bleeding, splenomegaly, distended veins, edema and hepatic encephalopathy. Serum aminotransferase and bilirubin levels are only minimally to moderately elevate usually but also may be normal.1, 2, 10, 23 Our patient had gradual abdominal distension, occasional abdominal pain, hepatosplenomegaly, ascites and liver function test was normal. Histological finding of veno-occlusive disease, chronic passive congestion and chronic Budd-Chiari syndrome is indistinguishable by microscopy. Acute Budd-Chiari syndrome can present with similar clinical findings but usually present with intractable ascites, abdominal pain, hepatomegaly, renal failure, the elevation of hepatic enzymes and coagulopathy.․ Our case had ascites, hepatomegaly and occasional abdominal pain since 2 years of life which are the classical presentation of Budd-Chiari syndrome.
Presence of some condition like: a) Abrupt onset of ascites and painful hepatomegaly; b) massive ascites with relatively preserved liver functions; c) sinusoidal dilation in liver biopsy without heart disease; d) fulminant hepatic failure associated with hepatomegaly and ascites; e) unexplained chronic liver disease; and f) liver disease with thrombogenic disorder when present, Budd-Chiari syndrome should be suspected.24 Our patient had massive ascites with preserved hepatic function.

The highly specific investigation for Budd-Chiari syndrome is doppler ultrasonography of hepatic vessels and inferior vena cava and it is the first step in evaluation to find out hepatic venous outflow obstruction. Stenosis, thrombosis, fibrotic cord or insufficient recanalization of the hepatic or caval vessel along with caudate lobe hypertrophy in doppler ultrasonography are highly specific for Budd-Chiari syndrome.12 Caudate lobe hypertrophy usually causes extrinsic compression of the inferior vena cava but this finding is less common in children than the adult.25 Other imaging findings include no flow signal and with spider-web appearance in hepatic veins, hepatic venous collateral circulation and stagnant, reversed or turbulent flow.

No visualization of hepatic veins or tortuosity is non-specific but most common sonographic findings of Budd-Chiari syndrome. 3 In our case color doppler study showed middle hepatic vein compressed due to enlarged caudate lobe, loss of normal flow characteristics, hepatofugal flow direction and features of mild portal hypertension indicating Budd-Chiari syndrome but no thrombosis in hepatic outflow was found.

Magnetic resonance imaging, computer tomography scan, magnetic resonance angiography, hepatic venography are other second-line imaging modalities which are required to find out any thrombosis and its exact location. Spider-web pattern on hepatic venography or presence of obstacle or its consequences, the collaterals to hepatic veins or inferior vena cava is diagnostic of Budd-Chiari syndrome. 3 In our patient, computer tomography scan of hepatic vessels revealed portal vein is dilated, tortuous and produces varices along with the spleno-portal circulation but no thrombosis was found. When these investigations failed to demonstrate the site of obstruction or any thrombosis then these patients need hepatic/inferior vena caval angiography for confirmation of hepatic venous/ inferior vena caval obstruction site or presence of thrombus. 26 In our case, we could not do hepatic/ inferior vena caval angiogram due to refusal of the patient party for financial constraint.

Serum bilirubin, aminotransferase levels, alkaline phosphatase and albumin should be done to see hepatic function. Histological findings by liver biopsy of Budd-Chiari syndrome are congestion, 
liver cell loss and fibrosis predominantly located in the centrilobular area. Liver biopsy is important in the differentiation of Budd-Chiari syndrome from veno-occlusive disease but not for a diagnosis. 27 Our patient had a normal liver function and thus we didn't do a liver biopsy.

For differentiation between Budd-Chiari syndrome and cardiac disorders like tricuspid regurgitation and constrictive pericarditis echocardiography is helpful. To find out the etiology of Budd-Chiari syndrome hemogram, evaluation of peripheral blood, determination of coagulation factors and inhibitors, genetic tests for factor $\mathrm{V}$ and prothrombin mutation, determination of anti-phospholipid antibody, lupus anticoagulant and flow cytometry for paroxysmal nocturnal hemoglobinuria should be performed. For the diagnosis of primary myeloproliferative disorder and determination of total red cell mass bone marrow biopsy may be helpful.27 Our patient had normal hemogram, echocardiography and we found a deficiency of protein $S$ and antithrombin III. So, the patient is on hypercoagulable state due to inherited thrombophilia.

Dr. Hassan: The therapeutic algorithm for BuddChiari syndrome is supportive, medical management of complications, surgical management and liver transplantation. It depends on the chronicity and site of the obstruction, the degree of liver dysfunction in children. Medical, surgical and endovascular therapeutic are options for the treatment of this condition. Initial medical therapy is conservative emphasizing diuretics, therapeutic paracentesis, treatment of predisposing factors, control of portal hypertension and prophylactic anticoagulation to decrease the risk of additional thrombosis.10,24 Inferior vena caval reconstruction with a pericardial patch, portosystemic shunts, mesoatrial shunts, portoatrial shunts, membrane resection and liver transplantation are the surgical options. Liver transplantation is an appropriate option in patients with long-standing obstruction, having evidence of severe portal hypertension or synthetic dysfunction..$^{1,28}$ Endovascular management options are stent placement, balloon angioplasty, catheter-directed thrombolysis, thrombus maceration and transjugular intrahepatic portosystemic shunt for of BuddChiari syndrome. 29 In our patient, we managed by giving diuretics and therapeutic paracentesis.

Dr. Mobasher: Important negative prognostic indicators include ascites, encephalopathy, elevated prothrombin time, and altered serum levels of sodium, creatinine, albumin, and bilirubin, cirrhosis and the presence of portal hypertension. $\underline{30}$ In our case, features of portal hypertension is developing so, the prognosis is guarded.

Dr. Ayesha Siddiqua (Resident): Why the prophylaxis of anticoagulant is not given?

Dr. Mazumder: As we don't find any thrombosis and as well as the patient had developing varices. 1 And the patient refuses to take warfarin prophylaxis due to its regular monitoring schedule.

Dr. Urmi Roy (Resident): Is there any other treatment option?

Dr. Dipanwita Saha (Fellowship Course): Yes, as this patient had a long-standing obstruction and evidence of severe portal hypertension present so liver transplantation is definitive treatment option. $\underline{28}$

Dr. Umma Jannatul Ferdous (Resident): What is the treatment option if medical therapy fails?

Dr. Nahid-E-Subha (Fellowship course): Liver transplantation is needed when medical treatment fails. $\underline{28}$

Dr. Ranjit Kumar (Resident): Why did you do echocardiography?

Dr. Benzamin (Resident): To exclude cardiac disorders like constrictive pericarditis, right heart failure, etc which are not associated with Budd-Chiari syndrome. $\underline{1-3}$

Dr. Badrun Nahar (Resident): Is there any chance of developing chronic liver disease in Budd-Chiari syndrome?

Dr. Fahmida: Longtime obstruction in the hepatic vein causes centrilobular necrosis and peripheral lobular fatty change due to hypoxic damage of hepatocytes followed by ischemia. If this condition chronically persist progressive fibrosis, nodular regenerative hyperplasia, cirrhosis and portal hypertension may develop during the course of disease and ultimately the development of the chronic liver disease may occur. $\underline{3}$

Dr. Sharmistha Ghosal (Resident): How will you differentiate acute from chronic Budd-Chiari syndrome clinically?

Dr. Md. Saidul Islam Sumon (Resident): Acute BuddChiari syndrome develops usually within 1 month or symptomatic for less than 6 months and chronic with disease duration of 6 or more months or signs of PHT present. 9

Dr. Rafiqul Islam (Resident): What are the common causes of Budd-Chiari syndrome?

Dr. Ahmadur Rahman (Resident): Common causes are inherited or acquired hypercoagulable state due to factor $\mathrm{V}$ Leiden and prothrombin mutation, deficiency of protein $\mathrm{C}$, protein $\mathrm{S}$ and antithrombin-III. 1 , $\underline{24,27}$

Dr. Raihanur Rahman (Resident): What is the indication of liver biopsy in Budd-Chiari syndrome?

Dr. Nahid-E-Subha (Resident): It may help in the differentiation of Budd-Chiari syndrome from veno -occlusive disease but not for a diagnosis. Congestion, liver cell loss and fibrosis predominantly located in the centrilobular area are findings in liver 
biopsy..$\underline{27}$

Dr. Nazmul Ahmed (Resident): What are the prognostic factors in Budd-Chiari syndrome?

Dr. Ruhina Tasmeen (Resident): Bad prognostic indicators include ascites, encephalopathy, elevated prothrombin time, and altered serum levels of sodium, creatinine, albumin, and bilirubin, cirrhosis and the presence of portal hypertension. $\underline{30}$

\section{Follow-up}

The patient was improved clinically and biochemically after 3 months of treatment and then further treatment continues accordingly.

\section{Final Diagnosis}

Chronic Budd-Chiari syndrome due to inherited thrombophilia (deficiency of protein $S$ and antithrombin III)

\section{Acknowledgement}

We are grateful to Prof. A. K. M. Fazlul Bari, National Institute of Nuclear Medicine and Applied Science, Bangabandhu Sheikh Mujib Medical University, Dhaka, Bangladesh for color doppler examination of hepatic and portal vasculature.

\section{Conflict of Interest}

The authors declare no conflict of interest.

\section{References}

1. Campbell K. Systemic disease and the liver. In: Liver disease in children. Suchy FJ, Sokol RJ, Balistreri WF (eds). $4^{\text {th }}$ ed. Cambridge, Cambridge University Press, 2014, pp 694-99.

2. Kathuriaa R, Srivastavaa A, Surender K, Yachhaa SK, Poddar U. Budd-Chiari syndrome in children: Clinical features, percutaneous radiological intervention, and outcome. Eur J Gastroenterol Hepatol. 2014; 26: 1030-38.

3. Aydinli M, Bayraktar Y. Budd-Chiari syndrome: Etiology, pathogenesis and diagnosis. World J Gastroenterol. 2007; 13: 2693-96.

4. Zanetto A, Pellone M, Senzolo M. Milestones in the discovery of Budd-Chiari syndrome. Liver Int. 2019; 39: 1180-85.

5. Valla DC. The diagnosis and management of the Budd-Chiari syndrome: Consensus and controversies. Hepatology 2003; 38: 793-803.
6. DeLeve LD, Valla DC, Garcia-Tsao G. Vascular disorders of the liver. Hepatology 2009; 49: 1729-64.

7. Shin N, Kim YH, Xu H, Shi HB, Zhang QQ, Colon Pons JP. Redefining Budd-Chiari syndrome: A systematic review. World J Hepatol. 2016; 8: 691702.

8. Janssen HL, Garcia-Pagan JC, Elias E, Mentha G, Hadengue A, Valla DC. Budd-Chiari syndrome: A review by an expert panel. J Hepatol. 2003; 38: 36471.

9. Valla DC. Hepatic vein thrombosis (Budd-Chiari syndrome). Semin Liver Dis. 2002; 22: 5-14.

10. Hector F, George B, Jorge L. Budd-Chiari syndrome. American J Roentgenol. 2012; 199: 737-45.

11. Dilawari JB, Bambery P, Chawla Y, Kaur U, Bhusnurmath SR, Malhotra HS. Hepatic outflow obstruction (Budd-Chiari syndrome): Experience with 177 patients and a review of the literature. Medicine 1994; 73: 21-36.

12. Boozari B, Bahr MJ, Kubicka S. Ultrasonography in patients with Budd-Chiari syndrome: Diagnostic signs and prognostic implications. J Hepatol. 2008; 49: $572-80$

13. Garcia-Tsao G, Friedman S, Iredale J, Pinzani M. Now there are many (stages) where before there was one: In search of a pathophysiological classification of cirrhosis. Hepatology 2010; 51: 1445-49.

14. Lee UE, Friedman SL. Mechanisms of hepatic fibrogenesis. Best Pract Res Clin Gastroenterol. 2011; 25: 195-206.

15. Shepherd RW, Ramm GA. Fibrogenesis and cirrhosis. In: Walker's Pediatric gastrointestinal disease. $6^{\text {th }}$ ed. North Carolina, People's Medical Publishing House, 2018, pp 2984-3025.

16. Chen WS, Leu SY, Lin JK, Lin TC. Trend of large bowel tuberculosis and relation with pulmonary tuberculosis. Dis Colon Rectum. 1992; 35: 189-92.

17. Kaba Ö, Kara M, Odacılar CA, Kamer İ, Sütçü M, Demir SÖ, Calışkan E, Törün SH, Salman N, Somer A. Evaluation of cases of pediatric extrapulmonary tuberculosis: A single center experience. Turk Pediatri Ars. 2019; 54: 86-92.

18. Islam Z, Sanin KI, Ahmed T. Improving case detection of tuberculosis among children in Bangladesh: Lessons learned through an implementation research. BMC Public Health, 2017; 17: 131.

19. M Ismail, G Azam. Abdominal tuberculosis. Med Today. 2016; 28: 39-45.

20. Rahman MM, Ahman, Haque KM, Siddiqui MM, Parvin T, Ahmed MK. Budd Chiari Syndrome: A case report. Univ Heart J. 2007; 3: 80-82.

21. Mahmoud AE, Helmy AS, Billingham L, Elias E. Poor prognosis and limited therapeutic options in patients with Budd-Chiari syndrome and portal venous system thrombosis. Eur J Gastroenterol Hepatol. 1997; 9: 485-89. 
22. Senzolo M, Cholongitas EC, Patch D, Burroughs AK. Update on the classification, assessment of prognosis and therapy of Budd-Chiari syndrome. Nat Clin Pract Gastroenterol Hepatol. 2005; 2: 18290.

23. Naomi S, Young H, Hao X, Yi X, Fei-Yun W, Samuel $\mathrm{H}$, Byung-Boong L, Lin-Sun Li. Redefining BuddChiari syndrome: A systematic review. World J Hepatol. 2016; 8: 691-702.

24. Menon KV, Shah V, Kamath PS. The Budd-Chiari syndrome. N Engl J Med. 2004; 350: 578-85.

25. Amarapurkar DN, Punamiya SJ, Patel ND. Changing spectrum of Budd-Chiari syndrome in India with special reference to non-surgical treatment. World J Gastroenterol. 2008; 14: 278-85.

26. Rajeev R, Anant B, Varun H, Vinod R, Swathi C. Pediatric Budd-Chiari syndrome: A case series. Pediatrology 2018; 55: 871-77.

27. Acharya J, Westwood NB, Sawyer BM, Messinezy
M, Burroughs AK, Mehta AB, Pearson TC. Identification of latent myeloproliferative disease in patients with Budd-Chiari syndrome using Xchromosome inactivation patterns and in vitro erythroid colony formation. Eur J Haematol. 1995; 55: 315-21.

28. Klein AS. Management of Budd-Chiari syndrome. Liver Transpl. 2006; 12: 23-28.

29. Garcia-Pagán JC, Heydtmann M, Raffa S, Plessier A, Murad S, Fabris F, Vizzini G, Abraldes JG, Olliff S, Nicolini A, Luca A. TIPS for Budd-Chiari syndrome: Long-term results and prognostics factors in 124 patients. Gastroenterology 2008; 135: 808 $-15$.

30. Murad SD, Valla DC, De Groen PC, Zeitoun G, Hopmans JA, Haagsma EB, Van Hoek B, Hansen BE, Rosendaal FR, Janssen HL. Determinants of survival and the effect of portosystemic shunting in patients with Budd-Chiari syndrome. Hepatology 2004; 39: 500-08 